Provided for non-commercial research and education use. Not for reproduction, distribution or commercial use.

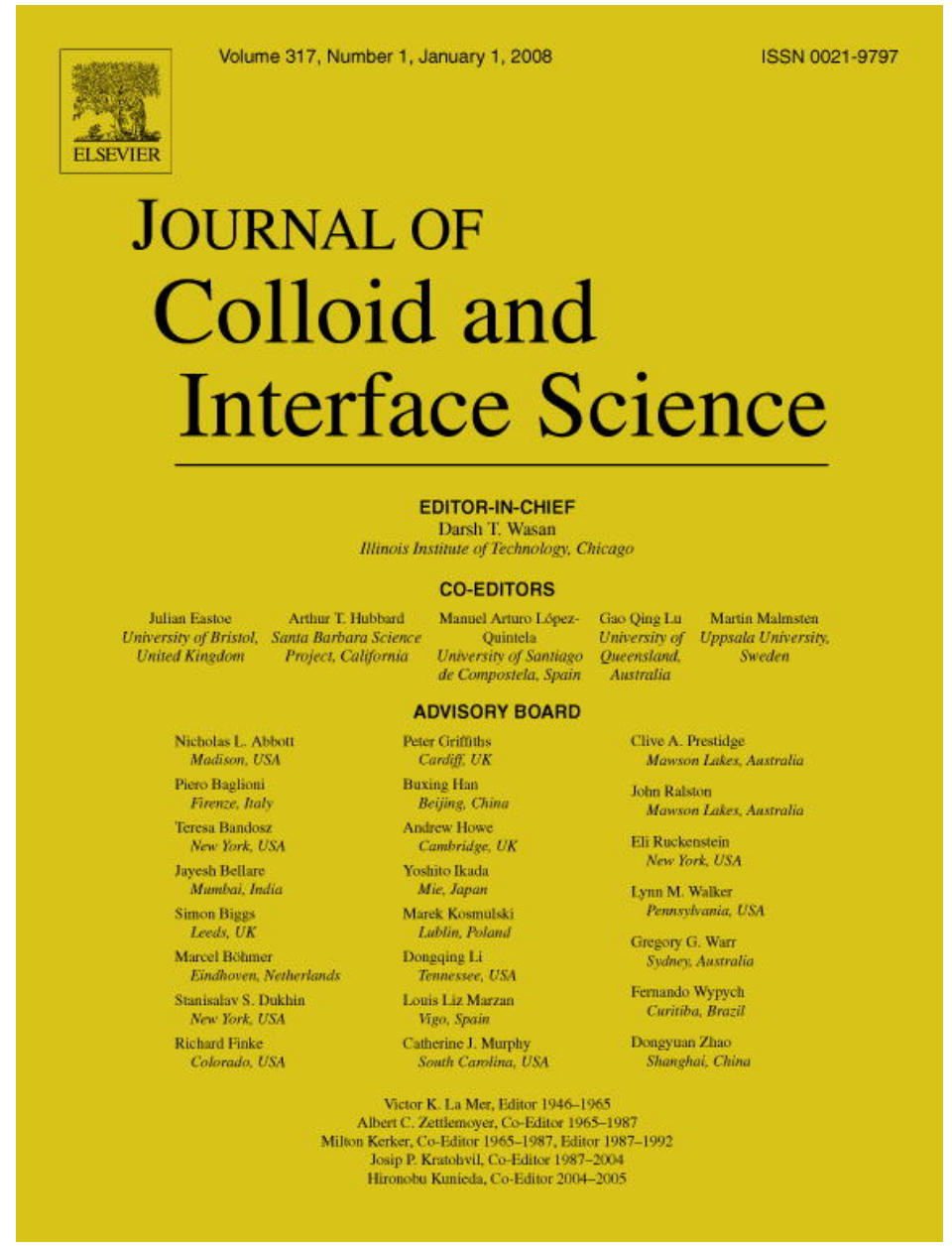

This article was published in an Elsevier journal. The attached copy

is furnished to the author for non-commercial research and education use, including for instruction at the author's institution, sharing with colleagues and providing to institution administration.

Other uses, including reproduction and distribution, or selling or licensing copies, or posting to personal, institutional or third party websites are prohibited.

In most cases authors are permitted to post their version of the article (e.g. in Word or Tex form) to their personal website or institutional repository. Authors requiring further information regarding Elsevier's archiving and manuscript policies are encouraged to visit: 


\title{
Adsorption mechanism of arsenate by zirconyl-functionalized activated carbon
}

\author{
Gerald T. Schmidt ${ }^{\text {a,1 }}$, Nataliya Vlasova ${ }^{\text {a,2 }}$, Damdinsuren Zuzaan ${ }^{\text {a }}$, \\ Michael Kersten ${ }^{a, *}$, Birgit Daus ${ }^{b}$ \\ ${ }^{a}$ Environmental Geochemistry Group, Institute of Geosciences, Johannes Gutenberg-University, 55099 Mainz, Germany \\ b Department Groundwater Remediation, UFZ-Helmholtz-Center for Environmental Research, 04318 Leipzig, Germany
}

Received 12 July 2007; accepted 6 September 2007

Available online 24 October 2007

\begin{abstract}
Arsenate $[\mathrm{As}(\mathrm{V})]$ and arsenite $[\mathrm{As}(\mathrm{III})]$ sorption at the solid-water interface of activated carbon impregnated with zirconyl nitrate (Zr-AC) was investigated using X-ray absorption spectroscopy (XAS) and surface complexation modeling. The XAS data at the Zr $K$-edge suggest that the structure of the zirconyl nitrate coating is built from chains of edge-sharing $\mathrm{ZrO}_{8}$ trigonal dodecahedra bound to each other through two double hydroxyl bridges. The 8-fold coordination of each $\mathrm{Zr}$ atom is completed by four $\mathrm{O}$ atoms, which share a bit less than the two theoretically possible bidentate nitrate groups. On impregnation, two of the $\mathrm{O}$ atoms may lose their nitrate group and be transformed to hydroxyl groups ready for binding to carboxylic or phenolic ligands at the AC surface. As $K$-edge XANES results showed the presence of only As(V) on adsorption regardless of the initial As oxidation state. Oxidation to $\mathrm{As}(\mathrm{V})$ is probably mediated by available carbon species on the $\mathrm{AC}$ surface as found by batch titration. $\mathrm{Zr}$ $K$-edge EXAFS data indicate that arsenate tetrahedra form monodentate mononuclear surface complexes with free hydroxyl groups of zirconyl dodecahedra, whereby each bidentate nitrate group is exchanged by up to two arsenate groups. The inner-sphere arsenate binding to the $\mathrm{Zr}$ - $\mathrm{AC}$ surface sites constrained with the spectroscopic results was used in the formulation of a surface complexation model to successfully describe the adsorption behavior of arsenate in the $\mathrm{pH}$ range between 4 and 12. The results suggest therefore that $\mathrm{Zr}$ - $\mathrm{AC}$ is an effective adsorbent for arsenic removal due to its high surface area and the presence of high affinity surface hydroxyl groups.
\end{abstract}

(c) 2007 Elsevier Inc. All rights reserved.

Keywords: Arsenate; Adsorption modeling; Activated carbon; Zirconyl; EXAFS

\section{Introduction}

The toxic and carcinogenic metalloid arsenic has caused major concerns in groundwater and wastewater quality assessments over the past few decades. Consequently many studies have been undertaken to develop and characterize arsenic cleanup techniques [1]. Among the solutions with the best potential to cover all the different spatial, temporal, and compositional scales at which contamination scenarios may occur are

\footnotetext{
* Corresponding author.

E-mail address: kersten@uni-mainz.de (M. Kersten).

1 Permanent address: DECHEMA Karl-Winnacker-Institut, Theodor-HeussAllee 25, 60486 Frankfurt am Main, Germany.

2 Permanent address: Institute of Surface Chemistry, National Academy of Sciences of Ukraine, General Naumov Str. 17, 03164 Kiev, Ukraine.
}

scavenging techniques of aqueous arsenic species by specific sorbents. In order to develop such remediation technologies, the adsorption capacity exhibited by each potential sorbent must be examined in relation to its regeneration behavior and cost. Not only should such techniques effectively remove arsenic from water but also be able to do so under the many different locally prevailing hydrochemical conditions. Other sorbates such as ambient major oxoanions could either become competitive or add to the value of the sorbent if no competitive effects deteriorate coadsorption efficiency. A sorbent which efficiently coadsorbs natural and anthropogenic organic pollutants would be particularly desired in the field of waste remediation technology. Mixtures of complementary sorbents for the removal of organic and inorganic species may prove less favorable with respect to their regeneration and cost $[1,2]$. Activated carbon (AC) functionalized by water-insoluble metal oxide impreg- 
nations serves as a favorable alternative for this purpose in that it contains an ensemble of independent monoprotic surface groups originating from both its carbon (e.g., surface carboxyls $-\mathrm{COOH}$ ) and its oxide (surface hydroxyls -OH; Refs. [1,2]). Since a large volume of research exists emphasizing iron oxides as efficient inorganic sorbents, it is not surprising that Fe-treated AC has recently been suggested for adsorption of arsenate and arsenite [3]. Use of rare oxides, e.g., titanium, ruthenium, and zirconium, has become cost beneficial due to the relatively low amount of material necessary for impregnating AC. Unlike with Fe oxides, these oxides are (i) inert to redox variations, (ii) have a much greater sorption capacity, and (iii) the presence of other oxoanions does not interfere significantly with the adsorption of As. Zirconium-loaded activated carbon was first used in analytical procedures as an adsorbent material for preconcentrating inorganic compounds of $\mathrm{As}(\mathrm{V}), \mathrm{Se}(\mathrm{IV}), \mathrm{Se}(\mathrm{VI})$, and $\mathrm{Hg}(\mathrm{II})$ in aqueous solutions [4,5]. Water-soluble zirconyl salts have been suggested in U.S. patents for functionalizing porous polymer resins and AC. Thus prepared $\mathrm{Zr}$-AC sorbents feature fast reaction kinetics, their sorption capacity for As is superior to that of Fe oxides, and its As load can readily be desorbed using alkaline (e.g., $\mathrm{NaOH}$ ) solutions [6]. However, the mechanism of As adsorption by $\mathrm{Zr}-\mathrm{AC}$ is not yet known in detail. This knowledge is required in order to predict sorption performance under specific conditions and thus develop an optimized filtering technique.

The effectiveness of the sorption processes suggests that As oxoanions may form inner-sphere complexes with $\mathrm{Zr}$-AC surface binding sites. If this is the case, X-ray absorption spectroscopy (XAS) should provide a useful tool for verifying the occurrence of such complexes and characterizing their molecular structure. In adsorption kinetics experiments using different sorbents and different As species, Zr-AC was found to remove aqueous $\mathrm{As}(\mathrm{V})$ faster than aqueous As(III), and faster than any other sorbent [6]. The kinetics of As(III) removal indicate that rate-limiting oxidation of As(III) to As(V) catalyzed by surficial carbon compounds may precede the adsorption reaction. This hypothesis is supported by the observation that the concentration of dissolved $\mathrm{As}(\mathrm{V})$ increased during the reaction even in an oxygen-free glove box in the presence of $\mathrm{AC}$, but not in the presence of any other inorganic sorbent [6]. A direct speciation of As sorbed on $\mathrm{Zr}$-AC using XAS experiments is thus warranted in order to confirm this hypothesis.

Chemical bonds between $\mathrm{Zr}$ and As are known from zirconium arsenates. These materials exhibit highly selective ionexchange behavior, which is determined by zeolite-like cavities in their layer structures. Only ions that are smaller than the cavities can diffuse into the lattice. A simple coprecipitation method of synthesis is based on mixing $\mathrm{As}_{2} \mathrm{O}_{5}$ and $\mathrm{Zr}$-dinitrate or $\mathrm{Zr}$ oxychloride in acidified solution, which forms $\alpha$-zirconium arsenate, $\mathrm{Zr}\left(\mathrm{HAsO}_{4}\right)_{2} \cdot \mathrm{H}_{2} \mathrm{O}$ [7-9]. Its $P 2_{1} / \mathrm{c}$ structure consists of layers of $\mathrm{ZrO}_{6}$ octahedra bridged through hydrogen arsenate moieties that alternate above and below the octahedral layers, with each arsenate tetrahedron bonding to three different $\mathrm{ZrO}_{6}$ octahedra [7,8]. Another method of synthesis employs hydrothermal treatment of an organic $\mathrm{Zr}$-propoxide solution mixed with $\mathrm{As}_{2} \mathrm{O}_{5}$ and urea, which forms $\gamma$-zirconium arsen- ate, $\mathrm{Zr}\left(\mathrm{AsO}_{4}\right)\left(\mathrm{H}_{2} \mathrm{AsO}_{4}\right) \cdot 2 \mathrm{H}_{2} \mathrm{O}$ [10]. Its somewhat more complicated $P 2_{1}$ structure consists of alternating layers of $\mathrm{ZrO}_{6}$ octahedra and $\mathrm{AsO}_{4}$ tetrahedra stacked along the 001 direction. Half of the arsenate groups share all four of their oxygen atoms with $\mathrm{ZrO}_{6}$ octahedra, while the other half are linked axially and possess two exchangeable protons each [10]. Since the formation of such compounds on adsorption of As onto the $\mathrm{Zr}-\mathrm{AC}$ surface cannot be excluded a priori, both $\mathrm{Zr}$-arsenate modifications were used as reference substances in the present study. If the formation of surface precipitates of these $\mathrm{Zr}$-arsenate compounds plays a role in the adsorption process, similarities in molecular structure between the references and the As-loaded $\mathrm{Zr}$-AC samples should show up in the characteristic features of their respective XAS spectra.

In the present study, the adsorption mechanisms of $\mathrm{As}(\mathrm{V})$ and $\mathrm{As}$ (III) on $\mathrm{Zr}$-AC were examined using a combination of macroscopic and microscopic techniques including extended X-ray absorption fine structure (EXAFS) spectroscopy and As batch adsorption experiments. The thus elucidated adsorption mechanisms were further used in formulating a surface complexation model to describe As adsorption behavior. The use of these rigorous analytical and modeling approaches enables the accurate determination of the adsorbed arsenic species essential for the prediction of adsorptive properties of these promising new adsorbents.

\section{Experimental}

\subsection{Sample preparation}

All stock solutions were prepared using ACS grade chemicals and deionized (DI) water. Granular AC purchased from Chemviron Carbon (Filtrasorb TL 830, bulk volume $1.6 \mathrm{~mL}$ $\mathrm{g}^{-1}$ ) was impregnated with dissolved zirconyl nitrate hydrate solution, $\mathrm{ZrO}\left(\mathrm{NO}_{3}\right)_{2} \cdot n \mathrm{H}_{2} \mathrm{O}$ (purum quality, Fluka 14985-18$3,25 \mathrm{~g} \mathrm{~L}^{-1}$, solution $\mathrm{pH} 1.3$ ), yielding a $\mathrm{Zr}$ concentration of $17 \mathrm{mg} \mathrm{g}^{-1}$ AC (XRF measurements; Ref. [6]). On thorough washing of the zirconyl-functionalized AC with DI water and gently drying at room temperature, specific surface areas were obtained from nitrogen adsorption isotherms at $77 \mathrm{~K}$ using a Micromeritics Gemini 2375 surface area analyzer (Micromeritics, Norcross, GA). The surface areas were determined from adsorption isotherms using the StarDriver v.2.03 software package associated with the surface area analyzer, which by means of the BET equation gave an $S_{\mathrm{BET}}=630 \mathrm{~m}^{2} \mathrm{~g}^{-1}$. Solutions of arsenic were prepared by diluting aqueous standards of As(III) $\left(\mathrm{NaAsO}_{2}, 0.05 \mathrm{molL}^{-1}\right.$, Merck) and $\mathrm{As}(\mathrm{V})\left(1000 \mathrm{mg} \mathrm{L}^{-1}\right.$, Merck Titrisol). Three subsamples were then loaded with different As concentrations. For this, a 2.0-g subsample of the $\mathrm{Zr}-\mathrm{AC}$ was shaken with a solution of either $\mathrm{Na}$-arsenate or $\mathrm{Na}$-arsenite (250 mL carbonate-buffered water solution with an initial As concentration of $200 \mathrm{mg} \mathrm{L}^{-1}$ ) for $24 \mathrm{~h}$. The resulting As loadings (dry weight) were $17.1 \mathrm{mg} \mathrm{g}^{-1}(\mathrm{As}(\mathrm{V})$ formulations) and $11.8 \mathrm{mg} \mathrm{g}^{-1}$ (As(III) formulations) as calculated from the final concentrations in solution (ICP-OES measurements) and confirmed by XRF measurements. Another As(III) sample was processed in an oxygen-free glove box by adding $1.0 \mathrm{~g} \mathrm{Zr}-\mathrm{Ac}$ 
to $250 \mathrm{~mL}$ Ar-purged arsenite standard solution $\left(50 \mathrm{mg} \mathrm{L}^{-1}\right)$. The sample was dried in the glove box (As concentration of $1.4 \mathrm{mg} \mathrm{g}^{-1}$ ) and stored under argon until XAS analysis.

\subsection{Potentiometric titration}

Potentiometric titration of the aqueous $\mathrm{Zr}$ - $\mathrm{AC}$ suspension ( $2 \mathrm{~g} \mathrm{~L}^{-1}$ ) with base was conducted at $25 \pm 0.1^{\circ} \mathrm{C}$ in $50-\mathrm{mL}$ polyethylene centrifuge tubes thermostated under an $\mathrm{Ar}$ atmosphere. The ionic strength was adjusted to 0.01, 0.05, and $0.1 \mathrm{M}$ using $\mathrm{NaNO}_{3}$ (Merck, p.a.). The $\mathrm{pH}$ of the suspension was measured using an Inolab Level2P pH meter (WTW) equipped with a combination electrode (SenTix81) and temperature probe. The electrode was calibrated using three-point commercial $\mathrm{pH}$ buffers (CertiPur, Merck). An initial solution of $0.1 \mathrm{M} \mathrm{NaOH}$ was prepared from standard solutions (Titrisol, Merck) and $\mathrm{CO}_{2}$-free Milli-Q water. The titrations were carried out in batch mode by discrete additions of diluted $\mathrm{NaOH}$ solution to the $\mathrm{Zr}-\mathrm{AC}$ suspension. Electrode readings were taken when a drift less than $0.002 \mathrm{pH}$ unit during 10 min was attained, with a minimum reading time of 20 min between additions.

\subsection{Batch adsorption experiments}

A stock solution of arsenate $(10.0 \mu \mathrm{M})$ was prepared by dissolving sodium arsenate heptahydrate $\left(\mathrm{Na}_{2} \mathrm{HAsO}_{4} \cdot 7 \mathrm{H}_{2} \mathrm{O}\right.$, Merck p.a.) and $25 \mathrm{~mL}$ of this solution was added to $50 \mathrm{mg}$ of $\mathrm{ZrAC}$ in each of 60 centrifuge tubes. The suspension $\mathrm{pH}$ was adjusted with $\mathrm{NaOH}$ solution under Ar. The closed centrifuge tubes were placed in a shaker and mixed for $24 \mathrm{~h}$ to reach equilibrium. The solid and solution were separated by centrifugation at $3300 \mathrm{~g}$ for $20 \mathrm{~min}$ and subsequent $0.2-\mu \mathrm{m}$ membrane filtration. The filtrate was acidified for storage until analysis for the nonadsorbed As fractions using a hydride generation AAS (Varian SpectrAAS) with a determination limit of $0.4 \mu \mathrm{g} \mathrm{L}^{-1}$. The amount of adsorbed arsenate was calculated as the difference between initial and equilibrium concentrations (\% adsorption of arsenate). Averages of duplicate adsorption batch experiments are reported, but for all a deviation of less than $10 \%$ was found.

\subsection{X-ray absorption spectroscopy}

For the powder XAS measurements, the reference and $\mathrm{Zr}$ $\mathrm{AC}$ samples were ground in an agate mortar and pestle together with polyethylene powder as a binding material and pressed to homogeneous tablets. The sample amount was chosen to achieve an edge step of about 1. Room-temperature measurements were made at Hamburg Synchrotron Laboratory (HASYLAB) beam line A1 in transmission mode both at the $\mathrm{Zr}$ $K$-edge $(17998 \mathrm{eV})$ and at the As $K$-edge $(11867 \mathrm{eV})$. Up to six scans per sample were collected and averaged to achieve an adequate signal/noise ratio. The first and the last As(III) spectra were compared to confirm that no photooxidation occurred during the sample analysis. Additional information regarding XAS data collection and processing is given in the Supporting Information.
Spectra averaging and deglitching were carried out using the WinXAS software package [11]. The codes Athena v.0.8.049 and Artemis v.0.8.006 included in the IFEFFIT software package [12] were used for the Fourier transform (FT) and inverse FT analysis. The $k$ ranges of the FTs were 2 to 12.5 and 2 to $16 \AA^{-1}$ for the $\mathrm{Zr} K$-edge and the As $K$-edge EXAFS, respectively. The Atoms and FEFF modules integrated in the Artemis code were used for calculating theoretical scattering paths. The ATOMS module was applied using crystal structure models of the references $\mathrm{Zr}$-dinitrate [13] and $\alpha$-zirconium arsenate [8]. Only single scattering paths were considered since no collinear multiple scattering paths were present in the models, and the contribution of noncollinear multiple scattering paths was found to be negligible. The fit ranges 1.8-4.2 $\AA$ ( $\mathrm{Zr}$ $K$-edge) and 1.4-4 $\AA$ (As $K$-edge) were selected to exclude the background signal.

\section{Results and discussion}

\subsection{Potentiometric titration}

The $\mathrm{NaOH}$ titration data were used to calculate the surface charge $\sigma_{0}$ of the $\mathrm{Zr}$-AC solid as a function of $-\log \left[\mathrm{H}^{+}\right]$presented in terms of $\mathrm{C} \mathrm{m}^{-2}$ by use of the equation

$\sigma_{0}=F \cdot\left(v_{\mathrm{a}} A-v_{\mathrm{b}} B+\left(\left[\mathrm{OH}^{-}\right]-\left[\mathrm{H}^{+}\right]\right)\left(v_{\mathrm{a}}+v_{\mathrm{b}}+v_{0}\right)\right) / S m$,

where $v_{0}$ is the initial volume of suspension taken for titration $(0.025 \mathrm{~L}) ; v_{\mathrm{a}}$ and $v_{\mathrm{b}}$ are volumes of acid and base with $A$ and $B\left(\mathrm{~mol} \mathrm{~L}^{-1}\right)$ concentrations, respectively; $S$ is the BET specific surface area $\left(630 \mathrm{~m}^{2} \mathrm{~g}^{-1}\right) ; m$ is the mass of the solid in the initial volume of suspension $(0.05 \mathrm{~g}) ; F$ is the Faraday constant $\left(96485 \mathrm{C} \mathrm{mol}^{-1}\right)$; $\left[\mathrm{H}^{+}\right]$is the proton concentration determined from the measured $\mathrm{pH}$ and the activity coefficients depending on the ionic strength of the background electrolyte $(\log \gamma=-0.05,-0.09$, and -0.11 for $0.01,0.05$, and $0.1 \mathrm{M}$ $\mathrm{NaNO}_{3}$ solutions, respectively). The titration curves obtained for different ionic strengths showed a common intersection point at $-0.076 \mathrm{Cm}^{-2}$. Since no acid had been added before titration, an initial pH 3.4 indicated that the samples obviously contained some acid impurities. The common intersection point represents the point-of-zero-salt effect ( $\mathrm{pH}_{\mathrm{PZSE}}$ ) which corresponds to the pristine-point-of-zero surface charge assuming symmetric background electrolyte ion sorption behavior. Modifying Eq. (1) yields

$\sigma_{0}=v_{\mathrm{a}} A-v_{\mathrm{b}} B+\left(\left[\mathrm{OH}^{-}\right]-\left[\mathrm{H}^{+}\right]\right)\left(v_{\mathrm{a}}+v_{\mathrm{b}}+v_{0}\right)=0$.

The residual acid concentration calculated from this equation is $0.48 \mathrm{mmol} \mathrm{g}^{-1}$, probably released as nitric acid during the binding of zirconyl nitrate in the microporous AC structure. The thus recalculated surface charge data as a function of $-\log \left[\mathrm{H}^{+}\right]$are presented in Fig. S1 in the supporting material. The corrected intersection point and real point of zero charge $\left(\mathrm{pH}_{\mathrm{PZC}}\right)$ is located at $-\log \left[\mathrm{H}^{+}\right]=6.9$. This is in good agreement with $\mathrm{pH}_{\mathrm{PZC}}$ values reported for pure $\mathrm{ZrO}_{2}\left(\mathrm{pH}_{\mathrm{PZC}} 6-7\right.$, Ref. [14]).

The equilibrium reaction constants were taken from the $\mathrm{pH}_{\mathrm{PZC}}$ value with the assumption of both a symmetrical proto- 
nation (i.e., $2 \mathrm{p} K$ model) and a symmetrical complex formation with background electrolyte ions:

$\mathrm{ZrOH}+\mathrm{H}^{+} \leftrightarrow \mathrm{ZrOH}_{2}^{+}, \quad \log K=6.9$,

$\mathrm{ZrOH} \leftrightarrow \mathrm{ZrO}^{-}+\mathrm{H}^{+}, \quad \log K=-6.9$,

$\mathrm{ZrOH}+\mathrm{H}^{+}+\mathrm{NO}_{3}^{-} \leftrightarrow \mathrm{ZrOH}_{2}^{+} \mathrm{NO}_{3}^{-}, \quad \log K=7.9$,

$\mathrm{ZrOH}+\mathrm{Na}^{+} \leftrightarrow \mathrm{ZrO}^{-} \mathrm{Na}^{+}+\mathrm{H}^{+}, \quad \log K=-5.9$.

Using the Basic Stern model, only capacitance values were fitted with GRFIT speciation code [15,16] for the surface charge curves at different ionic strengths $\left(C=0.4-0.5 \mathrm{~F} \mathrm{~m}^{-2}\right)$. Surface site density was estimated from the content of $\mathrm{Zr}$ on activated carbon surface, which was $17 \mathrm{mg} \mathrm{g}^{-1}$, and corresponds to $0.2 \mathrm{mmol} \mathrm{g}^{-1}$ or 0.18 sites nm ${ }^{-2}$. Calculated surface charge curves are presented in Fig. S1. Agreement between experimental and calculated curves is better below $\mathrm{pH}_{\mathrm{PZC}}$ but getting worse above $\mathrm{pH}$ 7. This may be due to some additional contribution to negative charge by the dissociation of surface groups of the carbon substrate [17]. Fitting at $\mathrm{pH}$ values above 7 was improved by assigning carboxylic surface groups with a $\mathrm{p} K$ 4.95 and a surface site density of $0.6 \mathrm{mmol} \mathrm{g}^{-1}$ to the AC substrate, which corresponds to 0.3 sites nm${ }^{-2}$. This value is in between 0.05 and 2.0 sites $\mathrm{nm}^{-2}$ reported in the literature for various AC types [17-20].

The titration curves of $\mathrm{Zr}$-AC suspension in the presence of arsenate at different ionic strengths also have a common intersection point but at a lower $-\log \left[\mathrm{H}^{+}\right]$value than those of pure Zr-AC suspension (Fig. S3 in supporting material). The adsorption of $325 \mu \mathrm{g} \mathrm{g}^{-1} \mathrm{As}(\mathrm{V})$ decreased the point of zero charge to a value of $\mathrm{pH}_{\mathrm{PZC}}=6.0$. The formation of outer-sphere surface complexes cannot shift this point because there are no specific chemical reactions between the adsorbate and the surface that could change the surface charge. The shift is rather an indication of the formation of inner-sphere negatively charged arsenate surface complexes similar to those commonly found on Fe oxide sorbents [21].

\subsection{As K-edge XAS}

The XANES spectra of different As-loaded Zr-AC samples measured at the As $K$-edge are all very similar to one another. The edge energy ranges from $11868.6 \mathrm{eV}$ (Zr-AC loaded with $\mathrm{As}^{3+}$, anoxic preparation) to $11869.9 \mathrm{eV}$ (Zr-AC loaded with $\mathrm{As}^{5+}$, high concentration). The white line is a relatively steep and narrow maximum in all spectra (Fig. S4 in supporting material). $\mathrm{As}(\mathrm{V})$ is the dominant species of all As samples, even in those which were originally loaded in As(III) solution in an oxygen-free glove box. Residual As(III) was not found to be sorbed onto $\mathrm{Zr}$-AC in detectable amounts. This result suggests that oxidation to $\mathrm{As}(\mathrm{V})$ has occurred at the $\mathrm{Zr}$-AC surface on adsorption of $\mathrm{As}(\mathrm{III})$ from solution probably due to the presence of reducible carbon species on the surface of AC.

The As $K$-edge EXAFS spectra are almost simple sinusoidal As-O wave functions without significant contribution from higher shells. This is confirmed by a very prominent first shell and low magnitudes of the higher shell peaks in the corresponding radial structure functions (RSF) as Fourier transform

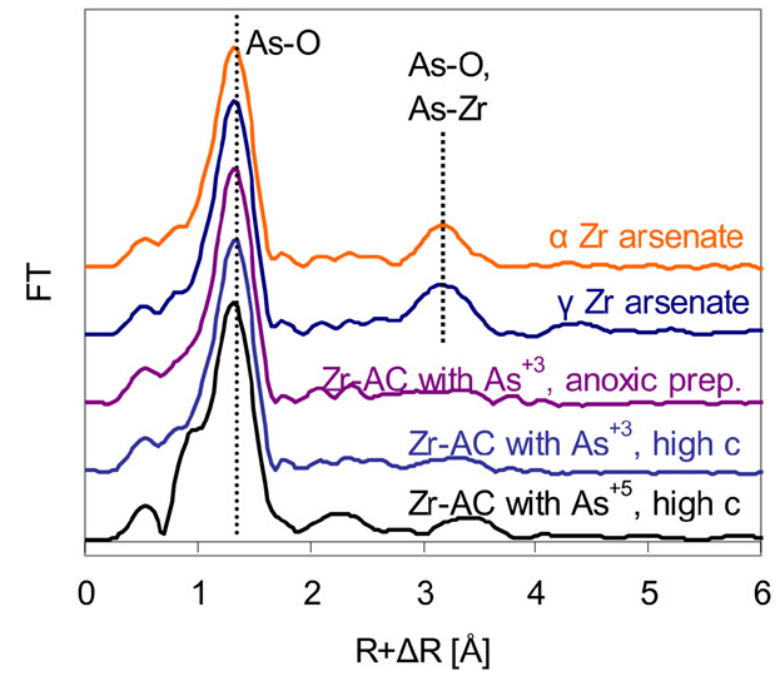

Fig. 1. As $K$-edge EXAFS FTs of zirconium arsenate reference materials and of $\mathrm{Zr}$-AC samples in the order of increasing As concentration (top to bottom).

(FT) vs radial distance plots (uncorrected for the phase shift: $R+\Delta R$; Fig. 1). Simulations performed with the $\alpha$-zirconium arsenate model (see Fig. S5 and Table S1 in supporting material) yield $4 \mathrm{O}$ shells with $R=1.68 \AA$ which are typical for arsenate tetrahedra. This is another clear indication that $\mathrm{As}(\mathrm{V})$ is predominant in the samples of all adsorption experiments, including those where $\mathrm{Zr}$ - $\mathrm{AC}$ was originally suspended in arsenite solutions. While a low amplitude of the As-O-Zr path measured at the As $K$-edge was already found for the synthetic $\alpha$-zirconium arsenate reference samples (Fig. 1), all of the signals at higher $R$ for the $\mathrm{Zr}$-AC samples were too low to obtain meaningful inverse FT fit results with sufficient accuracy. Qualitatively, one may conclude that the arsenate tetrahedra are not connected to as many $\mathrm{Zr}$ in $\mathrm{Zr}-\mathrm{AC}$ as in zirconium arsenate.

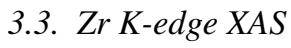

The XANES spectra obtained at the $\mathrm{Zr} K$-edge are shown in Fig. 2. The $K$-edge energy $E_{0}$ was found at $18009.9 \mathrm{eV}$ in the $\mathrm{Zr}$-dinitrate spectrum and $18009.7 \mathrm{eV}$ in all $\mathrm{Zr}$-AC spectra. Since $\mathrm{Zr}$ is known to occur only in the valence state +4 , $E_{0}$ would only change through major chemical alterations of $\mathrm{Zr}$ bonds, which obviously do not occur in the present case [22]. Some information about the near local surroundings of the central $\mathrm{Zr}$ atom can be inferred from the shape of the spectra [23]. The XANES of $\alpha$-zirconium arsenate, in which $\mathrm{Zr}$ is surrounded by six equidistant oxygen atoms in octahedral coordination, features a characteristic double hump. The octahedral arrangement of the oxygens in $\gamma$-zirconium arsenate is more distorted, which causes a different double-edged shape. $\mathrm{Zr}$-dinitrate, which is composed of zirconyl $\left(\mathrm{ZrO}_{8}\right)$ dodecahedra [13], shows only a single maximum in its XANES plot. The XANES spectra obtained from $\mathrm{Zr}$-AC samples are similar to each other and to that of the $\mathrm{Zr}$-dinitrate, which indicates that the dodecahedral arrangement of the $\mathrm{O}$ atoms around $\mathrm{Zr}$ did not change significantly during the impregnating of AC. Only at high As loading is the maximum slightly broader, indicat- 


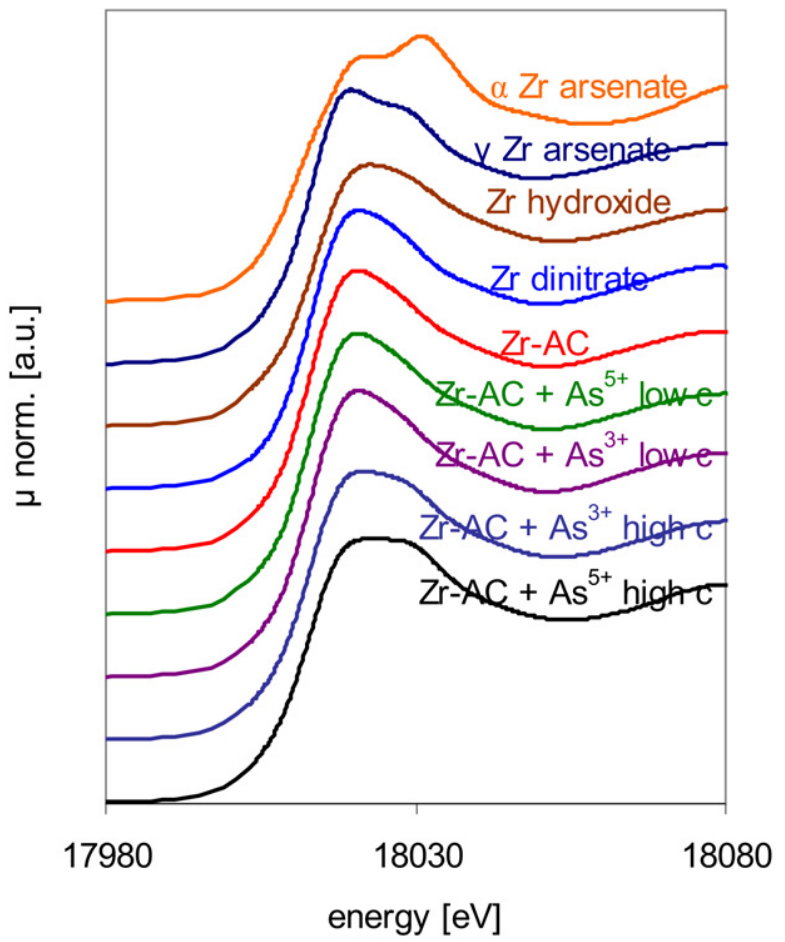

Fig. 2. Normalized $\mathrm{Zr} K$-edge XANES spectra of reference substances and $\mathrm{Zr}$-AC samples in the order of increasing As concentration (top to bottom).

ing some influence of As oxoanions on the $\mathrm{Zr}$ arrangement, which may be interpreted in terms of a reduced symmetry [24]. None of the spectra contain a shoulder shape in the absorption edge, ruling out tetrahedral coordination. Linear combination fits of reference XANES spectra by the Athena code (see Table $\mathrm{S} 2$ in supporting material) showed that the XANES features of $\mathrm{Zr}$-dinitrate dominate the spectra of all $\mathrm{Zr}$-AC samples. The fits with the spectra of the two samples with high As concentrations were improved by assigning a weight of up to $43 \%$ to the reference spectrum of $\alpha$-zirconium arsenate. This fact indicates the formation of some surface precipitate on overloading the system.

Fig. 3 shows the corresponding FT plots (uncorrected for the phase shift: $R+\Delta R$ ) for the $\mathrm{Zr} K$-edge EXAFS. The FTs of all reference substances are clearly different from those of the $\mathrm{Zr}$-AC samples. The Zr-dinitrate FT features a prominent first peak with an extended shoulder on its right side, which can be simulated in a two-shell single scattering model with $4 \mathrm{O}$ at $R=2.11 \AA$ (OH of zirconyl moieties), $4 \mathrm{O}$ with $R=2.25 \AA$ (O atoms of nitrate moieties), and $2 \mathrm{~N}$ with $R=$ $2.79 \AA$ ( $\mathrm{N}$ atoms of nitrate moieties). The $\mathrm{Zr}-\mathrm{O}-\mathrm{N}$ arrangement is obviously not linear but has a bonding angle of $160-170^{\circ}$ in agreement with the bidentate nitrate group binding to zirconyl edges known from the Zr-dinitrate structure. A linear arrangement would yield a slightly higher $\mathrm{Zr}-\mathrm{N}$ distance of $2.1(\mathrm{Zr}-\mathrm{O})+1.2(\mathrm{~N}-\mathrm{O})=3.3 \AA$. The second peak can be attributed to $2 \mathrm{Zr}$ with $R=3.53 \AA$. This value is significantly shorter than those found in all known zirconium basic salts (3.55-3.60 ̊) with the exception of basic nitrates. This is because double hydroxyl bridges act as bonding units in the zirconyl polymeric linkage. XRD refinement has shown that

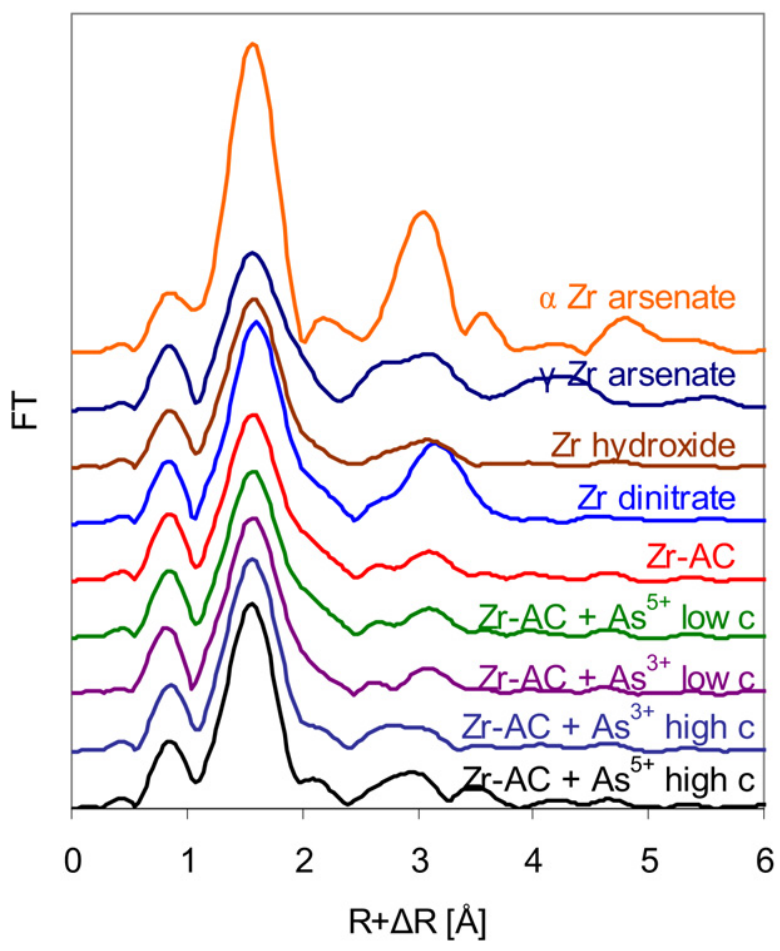

Fig. 3. Zr $K$-edge EXAFS FTs of reference substances and Zr-AC samples in the order of increasing As concentration (top to bottom).

the structure of $\alpha-\mathrm{Zr}(\mathrm{OH})_{2}\left(\mathrm{NO}_{3}\right)_{2} \cdot n \mathrm{H}_{2} \mathrm{O}$ is built from edgesharing zirconyl $\left(\mathrm{ZrO}_{8}\right)$ trigonal dodecahedra bound to each other through two common double hydroxyl edges forming infinite neutral zigzag chains of zirconyl dimers [13]. The 8-fold coordination of each $\mathrm{Zr}$ atom is completed by four $\mathrm{O}$ atoms from edge-sharing nitrate groups, i.e., four symmetrically independent bidentate $\mathrm{NO}_{3}$ groups for each zirconyl dimer moiety. The detailed results (including $\sigma^{2}$ values) of the FEFF fit are provided in Table S3 and Fig. S6 of the supporting material.

The plot of the pure $\mathrm{Zr}$-AC sample shows almost the same shape of the first peak as the Zr-dinitrate reference. As the arsenate load increases, the first peak in the Zr-AC FT plots becomes higher and narrower, but its shoulder remains at the same position. The second $\mathrm{Zr}$ shell peak appears then at an even lower $R+\Delta R$ but with a different shape (Fig. 3). The fit results listed in Table S4 (supporting material) indicate that the higher and steeper shape of the first peak with increasing As concentration can be attributed to increased $\mathrm{OH}$ coordination at $R=2.11 \AA$, and reduced $\mathrm{O}$ coordination at $R=2.25 \AA$. $\mathrm{Zr}$-AC samples without As contain nitrogen shells with a coordination number $N=2$, while samples with adsorbed As have a significantly lower coordination number $N=1.3$. No contribution of a $\mathrm{C}$ shell could be found for any of them. The $\mathrm{Zr}$ shell at $R=3.5 \AA$ is significantly reduced to a coordination number of now only 0.6 in all $\mathrm{Zr}$-AC samples compared to $N=2$ for the $\mathrm{Zr}$-dinitrate reference. This indicates that on impregnation by $\mathrm{Zr}$-dinitrate of the $\mathrm{AC}$ surface $\mathrm{Zr}-(\mathrm{OH})_{2}-\mathrm{Zr}$ chains of the edge-sharing zirconyl dodecahedra are broken, creating free $\mathrm{OH}$ groups on the remaining chain ends. In the plot of $\mathrm{Zr}-\mathrm{AC}$ with high $\mathrm{As}(\mathrm{V})$ concentration a third peak additionally appears at a higher $R+\Delta R$ position than the original second $\mathrm{Zr}$ shell 


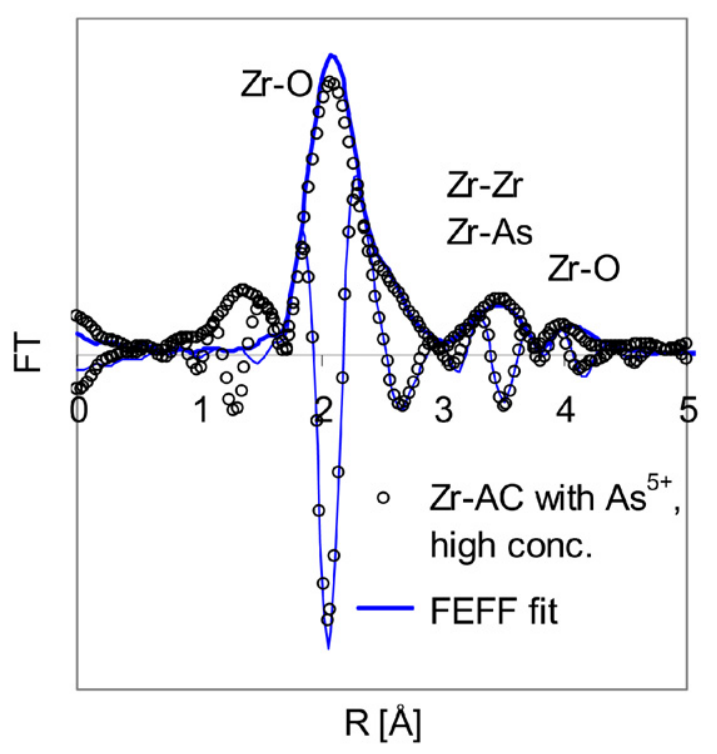

(a)

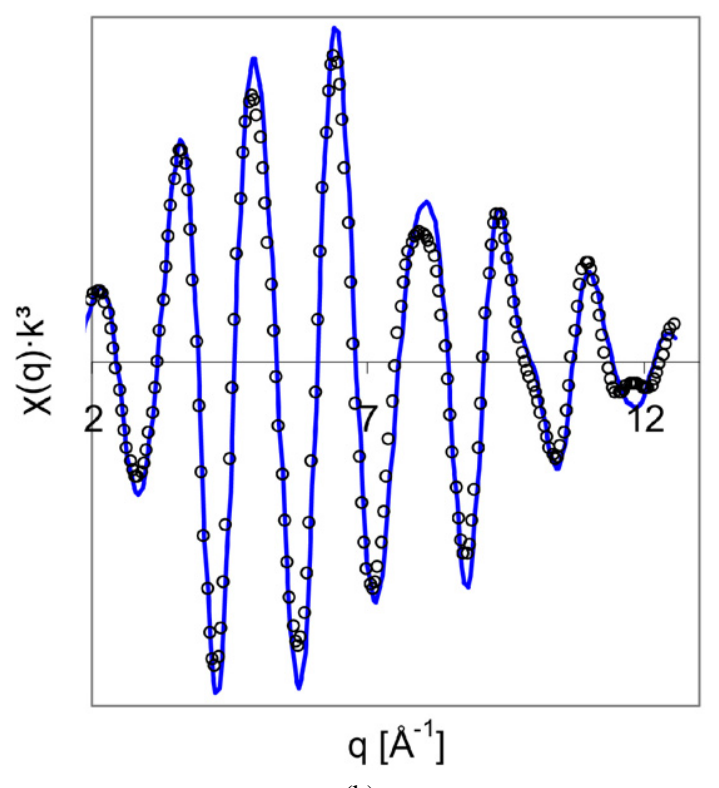

(b)

Fig. 4. (a) Modulus and imaginary part of the $\mathrm{Zr} K$-edge EXAFS Fourier transforms for the $\mathrm{Zr}$-AC sample with high $\mathrm{As}(\mathrm{V})$ concentration, and (b) real part of the inverse Fourier transform of $\mathrm{Zr}$ - $\mathrm{AC}$ in the (1.8-4.2 $\AA$ ) $R+\Delta R$ interval, both with FEFF simulations by the $\mathrm{Zr}$-dinitrate and $\alpha$-zirconium arsenate crystal structure models.

peak. FEFF fits (Fig. 4) were improved by including an additional As shell at $R=3.5 \AA(N=1.6-2.9)$ and a further $\mathrm{O}$ shell at $R=4.1 \AA(N=3.1-3.8)$. Fitting parameters for both shells (Table S4) were taken from the crystal structure model of $\alpha$-zirconium arsenate [8].

The $\mathrm{Zr}-\mathrm{As}$ distance at $3.5 \AA$ with $N \sim 2$ and a further $\mathrm{O}$ shell at $4.1 \AA$ are consistent with arsenate tetrahedra attached to corners of zirconyl dodecahedra. Obviously this is also not a linear $\mathrm{Zr}-\mathrm{O}-\mathrm{As}$ arrangement but must have a bonding angle of $130-140^{\circ}$. A linear arrangement would yield a $\mathrm{Zr}-\mathrm{As}$ distance of $2.1(\mathrm{Zr}-\mathrm{O})+1.7(\mathrm{As}-\mathrm{O})=3.8 \AA$. The bonding of arsenate tetrahedra to free hydroxyl sites would further promote

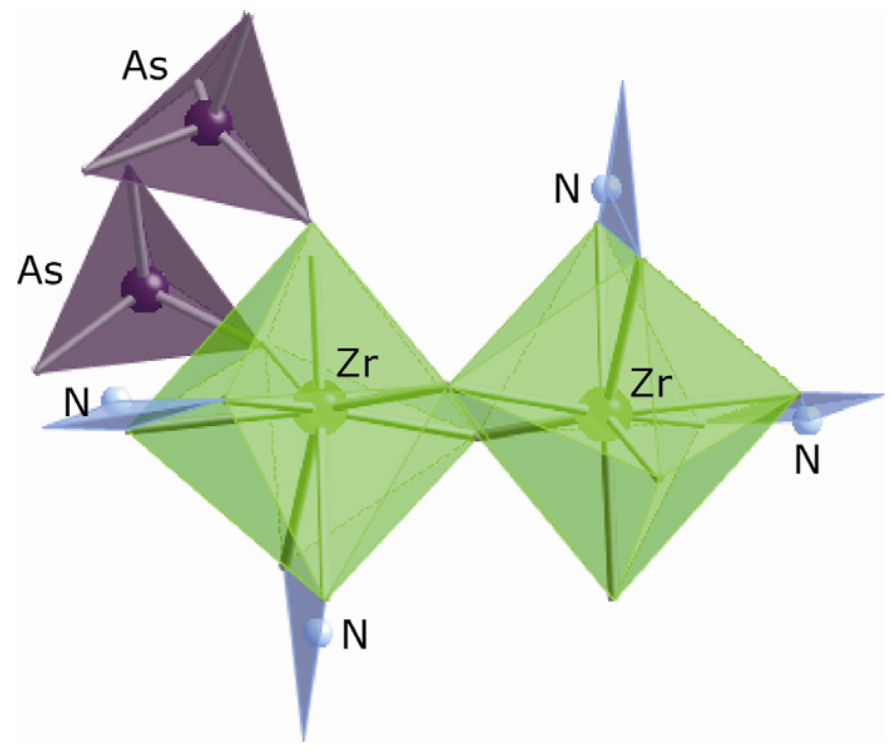

Fig. 5. Proposed molecular structure of $\mathrm{Zr}$-AC surface complex with mononuclear bidentate nitrate groups and monodentate arsenate tetrahedra adsorbed.

zirconyl chain cleavage as discussed above. The ultimate molecular structure of the nitrate and arsenate binding sites of the $\mathrm{Zr}$-AC surface proposed on basis of the FT analyses is shown in Fig. 5.

\subsection{Surface complexation modeling}

The calculation of equilibrium protonation and arsenate adsorption constants was again performed using the GRFIT speciation code $[15,16]$. The calculations had to consider dissolved speciation of arsenate using the following dissociation reactions and correspondent equilibrium constants [25]:

$$
\begin{aligned}
& \mathrm{H}_{3} \mathrm{AsO}_{4} \leftrightarrow \mathrm{H}_{2} \mathrm{AsO}_{4}^{-}+\mathrm{H}^{+}, \quad \log K=-2.2, \\
& \mathrm{H}_{2} \mathrm{AsO}_{4}^{-} \leftrightarrow \mathrm{HAsO}_{4}^{2-}+\mathrm{H}^{+}, \quad \log K=-7.0, \\
& \mathrm{HAsO}_{4}^{2-} \leftrightarrow \mathrm{AsO}_{4}^{3-}+\mathrm{H}^{+}, \quad \log K=-11.5 .
\end{aligned}
$$

The spectroscopic results indicated that the adsorbed As(V) species are negatively charged oxoanions with a mononuclear monodentate nonprotonated surface binding configuration. The Basic Stern surface complexation model was used to describe the arsenate adsorption on the $\mathrm{Zr}$-AC surface. The results of batch adsorption tests and BSM model calculations are shown in Fig. 6. The best match between experimental and calculated adsorption curves was obtained assuming the following complex formation reactions:

$$
\begin{aligned}
\equiv & \mathrm{ZrOH}+\mathrm{H}_{3} \mathrm{AsO}_{4} \leftrightarrow \equiv \mathrm{ZrOAsO}_{2}(\mathrm{OH})^{-}+\mathrm{H}^{+}, \\
& \log K=-2.5, \\
\equiv & \mathrm{ZrOH}+\mathrm{H}_{3} \mathrm{AsO}_{4} \leftrightarrow \equiv \mathrm{ZrOAsO}_{3}^{2-}+2 \mathrm{H}^{+}, \\
& \log K=1.4 .
\end{aligned}
$$

\section{Conclusions}

It was shown that a surface complexation model is well suited for fitting proton binding data and may therefore be 


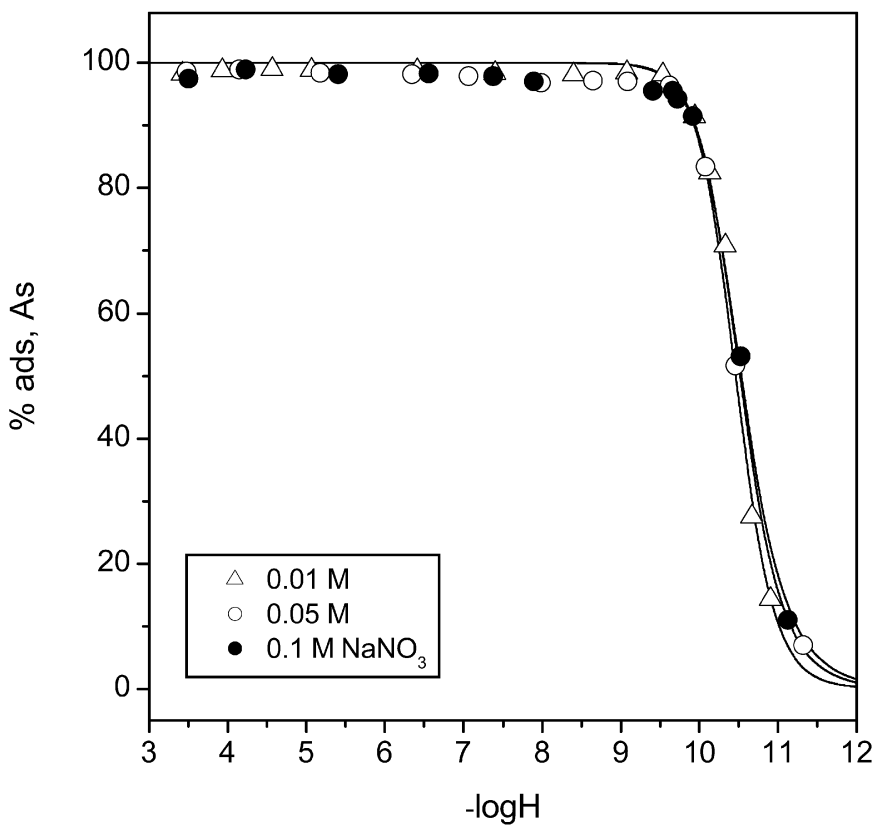

Fig. 6. Experimental (symbols) and GRFIT modeled (solid lines) data of arsenate adsorption onto $\mathrm{Zr}-\mathrm{AC}$ surface dependent on $\mathrm{pH}$ and ionic strength.

used for modeling arsenate adsorption. The Basic Stern model (BSM) was used to describe the surface charge of $\mathrm{Zr}-\mathrm{AC}$ and arsenate adsorption as a function of ionic strength and $\mathrm{pH}$. Surface speciation represented by the GRFIT model indicates two surface complexes, of which the first one represented by reaction (10) is practically negligible. Formation of the second one represented by reaction (11) which is a monodentate negatively charged inner-sphere surface complex $\equiv \mathrm{ZrOAsO}_{3}^{2-}$ is in agreement with the EXAFS data. In fact, $\mathrm{Zr}-\mathrm{As}$ distances of $3.5 \AA$ determined by the fit of the $\mathrm{Zr} K$-edge EXAFS data suggest inner-sphere binding of arsenate oxoanions to zirconyl cations in a single corner-sharing (i.e., a monodentate mononuclear) arrangement (Fig. 5). The monodentate binding is different from the bidentate binding common to $\mathrm{Fe}$ and $\mathrm{Al}$ oxides [26]. One zirconyl cation can thereby accommodate up to two arsenate anions at hydroxyl edges, which readily explains its high As sorption capacity [6]. The experimental observations and model fit showed that more than $98 \%$ of the dissolved arsenate was adsorbed by $\mathrm{Zr}-\mathrm{AC}$ in the $\mathrm{pH}$ range from 3 to 9 (Fig. 6). Adsorption efficiency drops below $10 \%$ as the $\mathrm{pH}$ increases above a value of 11 , which readily explains the favorable $\mathrm{Zr}$-AC sorbent regeneration performance using alkaline solutions [4-6].

\section{Acknowledgments}

We thank Dr. K. Klementiev for his assistance at the HASYLAB Beamline A1 and Dr. L. Szirtes for providing us with the $\alpha$-zirconium arsenate reference sample. This work was supported by the German Science Foundation (DFG) within the framework of the Interdisciplinary Research Training Group DFG 826.

\section{Supporting material}

The online version of this article contains additional supporting material including (i) three figures showing the surface charge of pure and As-loaded $\mathrm{Zr}-\mathrm{AC}$ as a function of ionic strength and $\mathrm{pH}$, with GRFIT curves for different model assumptions, (ii) two figures showing the EXAFS results of $\mathrm{Zr}$ dinitrate ( $\mathrm{Zr} K$-edge), $\alpha$-zirconium arsenate ( $\mathrm{Zr}$ and $\mathrm{As} K$ edges), and As-loaded Zr-AC (As $K$-edge) with FEFF fits, (iii) four tables showing the parameters obtained in these FEFF fits, and (iv) one figure showing the As XANES spectra of Asloaded $\mathrm{Zr}$-AC samples.

Please visit DOI: 10.1016/j.jcis.2007.09.012.

\section{References}

[1] D. Mohan, C.U. Pittman Jr., J. Hazard. Mater. 142 (2007) 1.

[2] G.S. Miguel, S.D. Lambert, N.J.D. Graham, J. Chem. Technol. Biotechnol. 81 (2006) 1685.

[3] K.B. Payne, T.M. Abdel-Fattah, J. Environ. Sci. Health A 40 (2005) 723.

[4] S. Peräniemi, S. Hannonen, H. Mustalahti, M. Ahlgrén, Fresenius J. Anal. Chem. 349 (1994) 510.

[5] A.M. Yusof, M.M. Rahman, A.K.H. Wood, J. Radioanal. Nucl. Chem. 259 (2004) 479

[6] B. Daus, R. Wennrich, H. Weiss, Water Res. 38 (2004) 2948.

[7] A. Clearfield, G.D. Smith, B. Hammond, J. Inorg. Nucl. Chem. 30 (1968) 277.

[8] A. Clearfield, W.L. Duax, Acta Crystallogr. B 25 (1969) 2658.

[9] L. Szirtes, J. Megyeri, L. Riess, E. Kuzmann, J. Therm. Anal. Calorim. 63 (2001) 117.

[10] J. Rodríguez, R. Llavona, M. Suarez, A.I. Bortun, A. Clearfield, Mater. Chem. Phys. 55 (1998) 152.

[11] T. Ressler, J. Synchr. Rad. 5 (1998) 118.

[12] B. Ravel, M. Newville, J. Synchr. Rad. 12 (2005) 537.

[13] P. Bénard-Rocherullé, J. Rius, D. Louër, J. Solid State Chem. 128 (1997) 295.

[14] M. Kosmulski, Chemical Properties of Material Surfaces, Surfactant Science Series, vol. 102, Dekker, New York, 2001.

[15] C. Ludwig, GRFIT: A program for solving speciation problems, evaluation of equilibrium constants, concentrations and their physical parameters, Internal Report, University of Berne, 1992.

[16] C. Ludwig, P.W. Schindler, J. Colloid Interface Sci. 169 (1995) 284

[17] R.C. Bansal, J.B. Donnet, F. Stoeckli, Active Carbon, Dekker, New York, 1998.

[18] M.O. Corapcioglu, C.P. Huang, Water Res. 21 (1987) 1031.

[19] A. Seco, P. Marzal, C. Gabaldon, J. Ferre, Sep. Sci. Technol. 34 (1999) 1577.

[20] C. Faur-Brasquet, Z. Reddad, K. Kadirvelu, P. Le Cloirec, Appl. Surf. Sci. 196 (2002) 356

[21] S. Goldberg, C.T. Johnston, J. Colloid Interface Sci. 234 (2001) 204.

[22] M.K. Gupta, A.K. Nigam, J. Phys. F Metal Phys. 4 (1974) 947.

[23] C. Meneghini, S. Mobilio, L. Lusvarghi, F. Bondioli, A.M. Ferrari, T. Manfredini, C. Siligardi, J. Appl. Cryst. 37 (2004) 890.

[24] P. Li, I. Chen, J.E. Penner-Hahn, Phys. Rev. B 48 (1993) 10063.

[25] M. Bissen, F.H. Frimmel, Acta Hydrochim. Hydrobiol. 31 (2003) 9.

[26] D.A. Sverjensky, K. Fukushi, Geochim. Cosmochim. Acta 70 (2006) 3778 . 